Access to this work was provided by the University of Maryland, Baltimore County (UMBC)

ScholarWorks@UMBC digital repository on the Maryland Shared Open Access (MD-SOAR) platform.

Please provide feedback

Please support the ScholarWorks@UMBC repository by emailing scholarworks-group@umbc.edu and telling us what having access to this work means to you and why it's important to you. Thank you. 


\title{
Net Neutrality or Minimum Quality Standards: Network Effects vs. Market Power Justifications
}

\author{
Timothy J. Brennan*
}

June, 2010

\begin{abstract}
Net neutrality - all bits should be treated identically by broadband Internet service providers regardless of source-is hotly debated. Proponents find adequate competition among broadband providers to prevent harm from content-based discrimination. Opponents find such regulation premature or unnecessary, noting that uniform treatment precludes higher quality services and effective congestion management. Both sides neglect network externalities - the value of broadband to each content provider depends on the expected quality of links to others' content. Competition could exacerbate this, as each provider fails to internalize the network externality. This suggests an alternative approach - a minimum quality of service standard. This addresses underlying concerns at far lower cost than net neutrality, while fostering innovation by allowing providers to offer higher quality service and manage congestion, with the ancillary benefit of protecting potential speech rights of content providers. Ex post antitrust remedies will not be available if judicial limits on FCC authority remain.
\end{abstract}

Keywords: net neutrality, telecommunications policy, network effects, regulation

JEL Codes: L96, L51, K20

\footnotetext{
${ }^{*}$ Professor, Public Policy and Economics, UMBC and Senior Fellow, Resources for the Future. Email: brennan@umbc.edu. Without implying responsibility for error or agreement with any of the views herein, I thank Richard Clarke, Greg Crawford, George Ford, Victor Glass, Molly Macauley, Mike Nelson, Tom Spavins, Menahem Spiegel, Gerry Wall, and participants in the 2007 Phoenix Center Annual U.S. Telecoms Symposium and Rutgers University Center for Research in Regulated Industries $29^{\text {th }}$ Eastern Conference for helpful discussions.
} 


\section{Introduction}

Today's leading telecommunications policy controversy is "network neutrality" $(\mathrm{NN}){ }^{1} \mathrm{NN}$ may be defined as a requirement that all Internet service providers (ISPs) treat each data packet identically. Some of the arguments from NN's advocates appeal to ISPs will deny a fair shake to the next garage-based innovator or capriciously deny service to those whose content it doesn't like, for example, cutting off access to a union's website during a labor dispute. Most of the arguments in favor of net neutrality, however, rely explicitly on market power. Absent appropriate regulations, $\mathrm{NN}$ proponents allege, ISPs will favor one supplier's content over another's. Consumers can typically choose from at most two providers of high speed broadband wireline services (cable television and telco DSL or fiber-optics), and that wireless services lack comparable speed or capacity.

Opponents of net neutrality claim that ISPs need to be able to discriminate in packet handling to manage congestion and latency to maintain quality of real-time services while peer-to-peer file sharing exhausts capacity. Other arguments, however, take issue with the premise underlying NN advocacy of market power and its consequences. Some suggest that two wire-based providers (cable television and telephone carrier digital subscriber line (DSL) or fiber-optic service) are enough for competitive conduct and that wireless broadband is also a relevant and important competitor. Even if an ISP has market power, moreover, limiting content penalizes it by reducing demand.

Our contribution here to this extensively debated issue is to propose an alternative to net neutrality—minimum quality standards. Such a policy is directly connected to the

\footnotetext{
${ }^{1}$ An important recent issue regarding policy implementation is whether the U.S. Federal Communications Commission (FCC) has the authority to require broadband providers to adopt $\mathrm{NN}$ or anything else. A recent D.C. Circuit Court of Appeals decision ruled that the FCC's statutory authority broadcasting and common carrier telecommunications did not extend to allowing it to prohibit Comcast, a cable broadband provider, from interfering with peer-to-peer transfers of large files, e.g., feature films. Comcast v. FCC (D.C.D.A.) slip op. (Apr. 6, 2010). The ruling was based on statutory, not constitutional, interpretation, however, so even if the decision were to stand after a Supreme Court review, Congress could grant the FCC's authority through appropriate legislation.
} 
network effects underlying the Internet, and avoids the overreaching inherent in $\mathrm{NN}$ advocacy and, thus making it unduly easy to come with arguments against regulatory intervention of any kind. In doing so, NN arguments should be divorced from market power considerations. A stronger rationale draws on the universal service argument that justified subsidies for traditional stand-alone voice service - that the value of voice service to one customer is enhance the more people that customer can call. It is for this reason, as well as lifting barriers to new entry, that telephone carriers are required to interconnect with each other, so each provider can reap the benefits of being able to access all subscribers regardless of their carrier.

For broadband Internet service, the analogous network effect is not across end users, but among content providers. The value of a website depends on the ability of other content providers to rely that links to it will operate. As with interconnection among voice providers, this network effects-based argument applies more strongly when there are numerous ISPs, where market power is not a concern. It suggests, accordingly, not full network neutrality based on mitigation of alleged market power. Rather, it suggests setting minimum quality standards to increase the value of links to all content suppliers. Importantly, minimum quality standards leaves ISPs relatively free to manage congestion and offer premium higher speed or latency-free services, with the attendant incentives to continue innovations to enhance the value of the Internet.

The paper proceeds as follows. The next section reviews a fairly extensive literature, generally policy-oriented rather than academic, to identify the leading arguments for and against NN mandates. On the pro-NN side, three stand out: (a) preventing broadband providers from tying content to the broadband service, (b) fostering price discrimination, particularly against content providers, and (c) inhibiting innovation by making it more expensive for unknown or unaffiliated entrepreneurs to obtain high speed or high quality access. A wider variety of arguments have been voiced against NN. The chief arguments against NN are that (a) the underlying markets are competitive, (b) providers with market power would not engage in NN that reduces demand for their services, and (c) the rules themselves may reduce competition, particularly by inhibiting the provision of specialized high-value services that require preferential treatment to eliminate latency and 
minimize risk of a transmission failure. This may become particularly acute as growth in demand for high-speed services, e.g., downloading high-definition video, imposes congestion that requires rationing of capacity.

The key focus of the debate is on the existence and effects of market power. As the thesis here is that the focus should be on network effects, the third section of the paper offer a very stylized model to illustrate the potential externalities created by degrading quality. To be tractable, the model abstracts from the determination of price and quality through strategic interactions among competing broadband providers, but instead looks at two geographically separate and noncompeting sets of regional broadband providers but where web content from customers one each network can be the targets of links on the other.

This gross simplification allows us to identify uncaptured gains from increasing quality on one network, even if each of the separate regions are achieving optimal prices and service quality in their regions. It also allows us to focus on these network externalities without getting mired in the difficulties of describing a multistage strategic equilibrium of quality and price determination. Even this simple model provides useful insights into the tradeoffs and considerations associated with a minimum quality-of-service response to net neutrality considerations, discussed in the following section.

We conclude with a reminder that if a lack of competition is the problem, antitrust enforcement would not be available unless Supreme Court or Congress does not reverse the D.C. Circuit's finding that the FCC lacks jurisdiction. Nor could a court impose a uniform quality standard, particularly if the sector is and remains workably competitive. A regulated quality of service remedy also has the side benefit of mitigating concerns that broadband providers have undue control over the free speech rights of content providers. Such a policy based on network effects, not market power, that mitigates harms of selective low quality service while allowing broadband providers to offer premium and innovative services to those willing to pay for them, provides an option that would not be merely a political compromise between two strongly opposed factions. It could well be the optimal thing to do. 


\section{Market power in the NN debate}

The quantity of material written on net neutrality is huge. As of May, 2010, a search of articles with "Net Neutrality" in the title turned up 46 papers on the Social Science Research Network; that phrase in abstracts and keywords adds another 44. Any summary is likely to miss some aspects of the discussion, but some themes emerge from many of these articles and papers. Ganley and Allgrove (2006), Schwartz and Weiser (2009) and Schuett (2010) provide some useful surveys of this extensive debate.

The main arguments in favor of net neutrality rely on a mistrust of the competitiveness of the underlying market for broadband access. One concern is that a vertically integrated broadband provider with market power will deny access to competitors of the affiliated service. An example would be forcing customers to use the broadband provider's voice telephone service rather than a stand-alone service. This essentially is a tying arrangement, in which one gets the underlying broadband connection only if one takes the affiliated service as well.

Outside the regulatory arena, tying arrangements generally promote economic efficiency. A broadband provider could presumably charge higher prices for its service and reap higher profits, the fewer restrictions it places on how its customers can use it. ${ }^{2}$ The profitability of tying the broadband service to affiliated content requires that those foregone profits be made up. One set of ways is through production efficiencies or demand enhancements, such as improved quality control, which respectively increase profits by cutting costs or expanding sales. The other is price discrimination, which tying arrangements can facilitate by charging price above cost to tied content and effectively charge higher prices to those who use broadband access more. Economists regard price discrimination in general as beneficial in that it provides incentives to firms, such as broadband providers, to expand output by selling services at low prices to those who with rela-

\footnotetext{
${ }^{2}$ Farrell and Weiser $(2008,105-119)$ offer arguments that communications firms with market power may not fully internalize the benefits from promoting competition in complementary content markets. Many of these, especially regulation of broadband, price discrimination, and strategic considerations, are considered in the discussion below.
} 
tively low willingness to pay (Carlton and Heyer, 2008; Iacobucci and Winter, 2009), without having to cut prices to those with greater willingness to pay.

There are exceptions. A first is if the tying were done to evade a regulatory price control on broadband service (Brennan, 2009a). On this account, discrimination against unaffiliated content providers in the quality or availability of access to a network by a price-regulated firm allows that firm to charge supracompetitive prices for its content, effectively exercising its market power over the underlying network in ways regulation was intended to thwart. A second consideration would be when tie changes the strategic considerations affecting entry into the broadband network or the related service, for example, by making credible a commitment to maintain output in the face of entry (Whinston, 1990). Neither of which the case, at least in the US. Broadband prices remain unregulated (Hahn and Wallsten, 2006), and it is difficult to imagine that broadband providers are deterring entry into broadband or content markets generally (beyond that which require broadband) by tying Internet-delivered content and broadband service together.

A second set of concerns has to do with the price structure implied by moving away from net neutrality. Both sides in the argument accept the premise that $\mathrm{NN}$ precludes charging content providers for access to the broadband network used to deliver that content to consumers (Schuett, 2010). Making carriage contingent on price inherently requires monitoring how much individual upstream content providers are using the network and excluding those who don't pay, thus violating the letter of NN. When markets are "two-sided," serving both upstream and downstream suppliers, such as broadband delivery, one would in general want to charge prices to customers both sides, here content providers and end users (who may be often be the same). The optimal price, however, can diverge from marginal cost when the value of the service to those on one side of the market depends on the number of customers on the other side (Rochet and Tirole, 2006). Generalities results on divergence sufficient to support charging positive prices only to end users are hard to come by. Economides and Tåg (2009) and Musacchio et. al. (2009) find that requiring a broadband monopolist to charge an upstream price of zero can increase net surplus, but may not do so. 
A stronger claim and one with more appeal in this context is that allowing broadband providers to charge content providers for delivery will impede innovation in content development. Lee and $\mathrm{Wu}$ (2009 at 66) argue that not charging content providers for access constitutes a "direct subsidy to the production of content and inventions [and] cheapens market entry by making it easier for users to switch and become content providers themselves," especially in the face of uncertainty as to whether one's content would become a "hit". These arguments are somewhat impressionistic, relying on the image of the Internet innovator as the little guy who will lose out if he can't match the payments of established content providers (Brennan, 2009b). Musacchio et. al. (2009 at 34-35) add that since content providers would have to pay multiple broadband providers for content delivery, one creates in effect a "successive monopoly" problem, where each broadband provider fails to consider how its pricing reduces the supply of content elsewhere.

A related concern is price discrimination. Choi and Kim (2008) argue that if broadband providers can discriminate in access, they have incentives to reduce investment in their networks to make it more worthwhile for content providers to pay for priority service. ${ }^{3}$ Krämer and Wieworra (2010) find, in contrast, the conventional result that price discrimination increases output by giving broadband providers the ability to charge low demand users without cutting rates charged to high demand users. The content providers are worse off, as the incentive to expand output comes from extracting surplus from the content providers. The difference between the two findings is at least in part related to Krämer and Wieworra's assumption that content providers are not competing with each other. When buyers compete, and thus have interdependent demands, price discrimination can raise price to everyone and reduce output and welfare (Katz, 1987).

Price discrimination could also deter upstream investment in innovative content. If a broadband provider has market power and can charge upstream fees, it may be unable to commit not to extract surplus from content innovators, and thus may deter innovation that would otherwise make it better off. Suppose that a content innovator would produce something that consumers would value collectively at $V$, net of the costs of delivery. If

\footnotetext{
${ }^{3}$ See also Economides (2008).
} 
the delivery sector were perfectly competitive, the content provider could capture all of that $V$. It would be willing to spend $C$ up to $V$ to develop the new service, and thus increase net economic welfare by $V-C$.

However, if $C$ is sunk and the delivery market is not competitive, the innovator would have to divide $V$ with the delivery providers. To take one example, if there were a delivery monopolist and both sides were otherwise equally positioned bargainers, the delivery provider and the content innovator would both get $V / 2$. One could imagine settings in which the delivery provider got more than $V / 2$ with even less left to the content innovator. Let $X<\mathrm{V}$ be the amount the innovator would retain. If $X<C<V$, the innovation would increase social welfare, but would not be profitable to the innovator and thus would not take place. That said, the iPhone, and Microsoft Windows before it, would at least appear to be counterexamples to the concern that a bottleneck monopoly impedes development of complementary products.

Opponents of net neutrality have other arguments as well. For the relevant short term, Sidak (2006) argues that net neutrality regulation would preclude offering of higher quality services and limits the ability of broadband operators to share in advertising revenues. These restrictions force end users to bear all of the costs of the broadband network, forcing prices higher than they might otherwise be and limiting the penetration of broadband service. Litan and Singer (2007) emphasize the inhibitions of efficient network use by forcing all users to obtain and pay for equal quality of service. Forcing all to pay for a uniform quality of service will inhibit demand from those who do not desire that level of quality and from those who would have preferred and been willing to pay for higher speeds and reduced latency.

Over the longer term, $\mathrm{NN}$ opponents argue that the inability to offer higher quality services to the subset of content providers willing to pay for them could inhibit innovation in the network. Yoo (2010) lends support to these points in describing in detail how the Internet is not monolithic, but rather a collection of heterogeneous networks with different costs and different interconnection rates, making uniform treatment even more problematic. Ford and Stern (2010) take a slightly different tack, suggesting that inability 
to charge content suppliers or make different service offerings will encourage providers to evade these restrictions through vertical integration, promoting the exclusivity that net neutrality regulations are intended to avoid.

Some opponents of net neutrality policies propose substitute policy responses. Faulhaber and Farber (2010) and Mayo et. al. (2010) recommend regulators should impose transparency rules instead of nondiscrimination or pricing regulations. These would allow the consumers to factor the policies regarding discrimination and congestion management, in choosing among providers. Market competition could then weed out those broadband providers whose upstream pricing, discrimination, or quality of service impose costs on consumers that exceed the benefits in improved marketing and network management. Hahn and Wallsten (2006) and Brito et. al. (2010) argue that one could bring antitrust cases against a broadband provider whose network management practices reduce competition.

All of these recommendations assume that the market is sufficiently competitive to allow the market to police quality choices and to put the case-by-case burden of proof on antitrust plaintiffs. Such optimism is consistent with NN opponents' view of the broadband delivery market. As long ago as 2006, Hahn and Wallsten (2006 at 5) stated that "90 percent of all zip codes in the U.S. had two or more broadband providers, and 75\% had three or more." Their article preceded the growth in wireless broadband access stimulated by the launch of the iPhone in 2007. In the joint filing of twenty-one economists to the FCC regarding broadband regulation, Brito et. al. (2010 at 8-9) concluded:

Virtually all of the available evidence suggests that broadband ISPs do not have significant market power in most markets. Moreover, the evidence demonstrates that broadband markets are becoming more, not less competitive, suggesting that any residual market power which may exist in the market for broadband ISP services is transitory.

\section{Content quality network externalities}

The key contention in these arguments is whether broadband providers have sufficient market power. If not, there is no problem. If so, the primary risks are alleged anti- 
competitive effects from discriminatory access and pricing. Along with those, some express intensely debated concerns that innovation by content providers or network providers would be inhibited if networks could charge content providers for preferential treatment. Some also suggest that a broadband network with market power would choose a combination of two-sided prices to upstream content providers and downstream end users that would be inefficient compared to charging zero prices and providing open access on the content side. Only Musacchio et. al. (2009) find a negative effect consistent with multiple providers, but they assume that each provider is its own monopoly, with the inefficiency resulting from multiple monopoly margins.

Most if not all of these arguments disappear if the relevant markets are competitive. Opponents of net neutrality exploit this by suggesting that a combination of transparency and the threat of antitrust enforcement will prevent the harms that NN is intended to address. Moreover, the opponents have a strong case in arguing that uniform service quality threatens reasonable congestion management. $\mathrm{NN}$ could also inhibit development of service offerings that require special or priority treatment, e.g., uses requiring elimination of latency, low error, or and particularly high bit transmission speeds.

What these leave open is the possibility that service quality may be inefficiently low even if markets are competitive. The argument is simple and although potentially novel in this context, is not novel in the history of telecommunications. It is essentially the traditional telephone universal service network externality flipped onto the content side. In the earlier context, a network could be undersubscribed because each individual's decision to obtain telephone service increased the network's value to other subscribers. In the present case of broadband Internet service, many content providers offer links to other sites. When that is undertaken, the value of access to that content provider of using the Internet depends not only on the quality of access she receives. It will also depend on her expectation that those who view her website will be able to connect to the sites to which she links at some level of acceptable quality. Consequently, quality of service limitations imposed by another's broadband provider, which may efficient relative to its own customers' demands, impose a negative externality on her and her broadband provider's customers. 
A simple and less-than-fully realistic model can illustrate this network effect. Suppose there are two regions, 1 and 2 . In each region are broadband providers that supply $n_{i}$ customers with quality $q_{i}, i=1,2$. The willingness to pay $W$ of the $n_{i}^{\text {th }}$ customer in Region $i$ for service depends both on the quality in its own market $q_{i}$, and in that in the other market, $q_{j \neq i}$. The costs of providing service in Region $i, C^{i}$, is a function of the number of subscribers $n_{i}$ and the quality level $q_{i}$ they obtain. ${ }^{4}$ To make the model tractable, we assume that each region has a single quality level. Using standard measures of surplus, the aggregate welfare $A^{1}$ from broadband service in Region 1, say, will be

$$
A^{1}\left(n_{1}, q_{1}, q_{2}\right)=\int_{0}^{n_{1}} W^{1}\left(z, q_{1}, q_{2}\right) d z-C^{1}\left(n_{1}, q_{1}\right) .
$$

To avoid complications of determining how quality would be determined in these markets and results that follow from those complications rather than the issue at hand, we assume idealized competition, namely, that $n_{i}$ and $q_{i}$ end up chosen to maximize $A_{i}$ in each region, given the quality level $q_{j \neq i}$ set in the other region. This assumption also bleeds market power out of the model, illuminating the arguments for or against broadband policies consistent with competition. Nevertheless, to avoid assuming the issue away altogether, we keep Regions 1 and 2 separate in the sense that providers in one region do not compete with the other. However, we retain the assumption that in each region, sufficiently idealized competition (or regulation) ensures that all quality is optimally set from that region's perspective.

With these assumptions, the following first-order conditions would determine $n_{1}$ and $q_{1}$, given $q_{2}$ :

$$
\frac{\partial A^{1}}{\partial n_{1}}=0 \Rightarrow W^{1}\left(n_{1}, q_{1}, q_{2}\right)=\frac{\partial C^{1}}{\partial n_{1}}
$$

\footnotetext{
${ }^{4}$ The number of subscribers in and of itself could make it more costly to provide a given level of quality, as more users would tend to congest the network - a negative "network effect". The general form of the cost function allows incorporation of those effects on the cost side.
} 


$$
\frac{\partial A^{1}}{\partial q_{1}}=0 \Rightarrow \int_{0}^{n_{1}} \frac{\partial W^{1}\left(z, q_{1}, q_{2}\right)}{\partial q_{1}} d z=\frac{\partial C^{1}}{\partial q_{1}}
$$

The first says that the price of adding a subscriber just equals the marginal cost of that subscriber. The second is that the marginal value of an increment to quality across all subscribers in a region just equals the marginal cost of that quality increment.

Total economic welfare, however, is the sum of $A^{1}$ and $A^{2}$.

$$
\int_{0}^{n_{1}} W^{1}\left(z, q_{1}, q_{2}\right) d z-C^{1}\left(n_{1}, q_{1}\right)+\int_{0}^{n_{2}} W^{2}\left(z, q_{1}, q_{2}\right) d z-C^{2}\left(n_{2}, q_{2}\right) .
$$

The values $n_{1}$ and $q_{1}$ that maximize $A^{1}+A^{2}$ are given by

$$
\begin{aligned}
& \frac{\partial\left(A^{1}+A^{2}\right)}{\partial n_{1}}=0 \Rightarrow W^{1}\left(n_{1}, q_{1}, q_{2}\right)=\frac{\partial C^{1}}{\partial n_{1}} \\
& \frac{\partial\left(A^{1}+A^{2}\right)}{\partial q_{1}}=0 \Rightarrow \int_{0}^{n_{1}} \frac{\partial W^{1}\left(z, q_{1}, q_{2}\right)}{\partial q_{1}} d z+\int_{0}^{n_{2}} \frac{\partial W^{2}\left(z, q_{1}, q_{2}\right)}{\partial q_{2}} d z=\frac{\partial C^{1}}{\partial q_{1}} .
\end{aligned}
$$

The first condition is the same as the above, without taking the second region into account; the price in Region 1 equals the marginal cost of supplying additional service to the broadband provider. The second equation differs from the above case, however. It adds the marginal value to Region 2 of increasing the quality of service provided in Region $1 .^{5}$ If that marginal value indicated by the second integral is positive, the optimum under idealized competition in Region 1 will result in too little quality. The price the Region 1 provider receives from Region 1 customers for added quality will not reflect the value of that quality reaped by the Region 2 provider and its customers.

\footnotetext{
${ }^{5}$ There would be a similar additional term if the number of subscribers in Region 1 affected the value of broadband access in Region 2. We neglect that here but return to it in the following discussion.
} 


\section{Lessons from the model}

This simplistic model illustrates the obvious point that if quality levels offered by one provider affect the value to other providers, quality will be underprovided absent some other arrangement to ensure that quality is at the desired level. One possibility would be an inter-carrier agreement on minimum quality rules, e.g., through a standard-setting organization. If such an agreement requires inter-carrier compensation, however, it may raise issues of collusion on price and other conditions of sale (Brennan, 1997) or monopsonization against upstream providers (Sidak, 2009). ${ }^{6}$ This will especially be the case if, as in the real world, the carriers are not separately ideal performers but overlapping, imperfectly competing differentiated oligopolists. The flip side of this coin is that this potential market failure would be less compelling if broadband providers possessed market power, as there would be fewer of them and this quality externality would be more likely to be internalized.

This leaves the public option, but not net neutrality. Addressing the network effect from complementary content provision across carriers does not require that everyone be treated equally. It justifies only a minimum standard, so someone who posts links on his website has reasonable assurance that the links will be available to those who view his website. Such policies are hardly unprecedented. In electricity, those who generate or sell electricity are typically obligated to meet reserve requirements because of the positive externalities produced by enhanced quality of service, which in that context is maintaining reserves to limit the probability of a blackout. The issue of having equipment meet standards to prevent harm to the network overall has long been a concern in telephony. ${ }^{7}$ Quality standards may be appropriate in cellular telephony as well (Government

\footnotetext{
${ }^{6}$ The Federal Trade Commission brought, initially won, but then lost on appeal a case claiming that Rambus had violated the antitrust laws by not disclosing that it had a patent over a technology chosen by a standard setting organization (Rambus, Inc. v. FTC, 522 F.3d 456, 469 (D.C. Cir. 2008). Such activities could be fraudulent, or breach disclosure terms in contracts for participation in a standard-setting organization, but it is not clear that they do or should fall under the realm of antitrust (Froeb and Ganglmair, 2009; Wright, 2009).

${ }^{7}$ The pre-divestiture AT\&T was accused of impeding competition by insisting on such standards. The response was not that such standards were inappropriate, but that AT\&T's control over such standards was
} 
Accounting Office, 2009), although the concern there may be centered more on consumer protection than creating expectations of a minimum level of service quality throughout a network. $^{8}$

A crucial advantage of minimum quality regulation over $\mathrm{NN}$ is that it does preclude offering better than the minimum quality, presumably at higher prices. The concerns that regulation would stifle innovation, product development, and customer service become less important, if not disappear altogether. The proposal also appears consistent with charging content providers for carriage, as long as the carriage is provided at a minimum quality level. Moreover, the quality standard could in principle be defined stochastically, that a minimum transmission speed would be achieved a certain fraction of the time, just as the old voice telephone network was designed to complete calls with a high probability.

A minimum quality standard is not without some potential drawbacks. Many of these are illustrated by the assumptions needed to produce the simple model above. A first is that in practice market imperfections could lead to super-optimal quality levels. It is well known that a monopoly may set quality above the optimal level if marginal increases in quality increase the willingness to pay of the marginal consumer more than they increase the marginal value of quality to the average inframarginal consumer. This seems unlikely to be satisfied with sufficient generality to eliminate minimum quality standards from consideration, if for no other reason that the broadband market may be sufficiently competitive to render this particular theoretical result in the monopoly context irrelevant in practice.

A more significant restriction in the model was that the network externality portrayed involved only quality, not the number of subscribers themselves. It is not difficult to show that if the effect on increasing quality is to reduce the marginal welfare of adding

a means for overcharging for customer premises equipment and thus evading direct regulation over telephone service rates.

${ }^{8}$ Hazlett (2003 at 171) also observes that quality standards set by regulation may be appropriate in cellular telephony if operators would promise higher quality than they intend to deliver. 
additional subscribers, a policy to increase quality might reduce subscribers. ${ }^{9}$ This would happen if the effect of incremental quality on marginal cost, and thus price, exceeded the value of that quality to the marginal customer. If so, the network externality benefits of setting a minimum quality standard could be less than the network externality costs from having fewer content providers (or other subscribers) overall.

The model also does not incorporate directly setting different quality levels to different customers. This may be particularly consequential if setting a minimum quality level for all reduces the quality level for which others might be willing to pay a premium. This could happen if there are adverse cost interactions, i.e., if increasing minimum quality increases the marginal cost of providing higher levels of quality. More likely, perhaps, is that as Choi and Kim's (2008) model suggests in the context of congestion, the demand for higher quality would fall if the low quality level were to increase. Such a reduction in demand could lead to lower quality offerings for those premium consumers. Finally, it is not difficult to imagine that this reduced demand could alter the strategic interaction among broadband oligopolists that tilts the equilibrium away from higher premium quality levels, although that possibility is not analyzed here.

If premium quality levels fall as a result of minimum quality standards the average quality could fall if a minimum quality level is imposed. If content providers value average overall quality in assessing their willingness to pay for and use broadband access, minimum quality standards could be counterproductive. On the other hand, if content providers are risk averse regarding the variance in quality, particularly to the point that they want something close to a guarantee that applies to all linked content. Regardless of whether that content provider chose premium access, minimum quality standards would continue to promote network externalities even if premium quality levels were to fall. In addition, increasing quality through the broadband sector could increase an individual content provider's demand for a high quality service, further enhancing the value of minimum standards as a policy option.

\footnotetext{
${ }^{9}$ To show this, differentiate the first-order condition for the number of subscribers, $\partial A^{1} / \partial q_{1}=0$, totally to find that $d n_{1} / d q_{1}=-A^{1}{ }_{n q} / A^{1}{ }_{n n}$. $A 1 n n$ is negative to satisfy the second-order condition that $n 1$ maximizes $A^{1}$, so $d n_{1} / d q_{1}<0$ if $A_{n q}^{1}<0$. This will be the case if increasing $q_{1}$ increases the marginal cost of a subscriber, $\partial C^{1} / \partial n_{1}$, by more than it increases the value of service to the marginal subscriber, $W^{1}\left(n_{1}, q_{1}, q_{2}\right)$.
} 


\section{Concluding observations: Implementation and alternatives}

The network neutrality debate has two flaws. The first is that the central concern, market power, misses the network nature of the Internet across providers, which is what should drive the policy. The second flaw, related to the first, is overreaching. NN does not follow directly from the market failure arguments, particularly those based on network effects, which could justify a regulatory response. This has lead to an unfortunately polarizing choice between highly intrusive regulation and no intervention at all. Minimum quality standards avoid both of these, as they are connected to the network effects and are amenable to a "more or less" rather than "all or nothing" assessment.

That said, the discussion here has avoided the crucial questions of what the standard should be and how much it would cost to implement it. While in theory quality may be too low, whether a standard close to the optimum can be designed is not obviously simple. Finding the optimal standard in principle involves comparing the network externality benefits of a minimum quality standard to the costs of implementation, monitoring and congestion management presented by such a standard. This requires being able to define "quality" in an operational way that corresponds to the aspects of service that generate content network externalities and can be monitored by those charged with enforcing minimum standards. ${ }^{10}$ Minimum standards also present the risk of suppressing some competition through quality differentiation. Standard setting through industry groups or the government could turn into a tool for inhibiting entry by new providers. Recognizing these difficulties, the costs of minimum standards appear far smaller than enforced uniformity through net neutrality rules.

It is also important to keep in mind shortcomings of other proposed remedies. Proposals to maintain transparency do nothing to address the network externality. That potential market failure is not based on the ignorance of individuals regarding their own broadband provider, but the inability to ensure minimum performance from others'

\footnotetext{
${ }^{10}$ Victor Glass has suggested that the statistical measures used to define service quality for voice telephony, emphasizing the probability of a busy signal due to network capacity limits, do not have ready analogues when it comes to providing specified levels of content quality.
} 
broadband providers. Moreover, transparency rules may inhibit innovation in congestion management. If such rules require disclosure of how a broadband provider deals with congestion, they may enable that provider's rivals to copy what that provider does, reducing the ability to appropriate the gains from novel approaches.

The other alternative remedy is ex post antitrust. As noted above, the network externality problem is not only consistent with competition, but is exacerbated by it, as the more providers there are, the less on average that any one of them would internalize the benefits of providing minimum quality standards. Moreover, recent Supreme Court, motivated by reasonable general concerns about the potential overreach of monopolization laws, have virtually immunized firms from antitrust liability when sector regulators have the authority to oversee pricing, entry, and competition (Brennan, 2008). If the D.C. Circuit's decision in Comcast v. FCC $C^{11}$ that limited FCC authority over broadband is not reversed by Supreme Court review or Congressional legislation, antirust oversight would likely not be viable. ${ }^{12}$ Thierer and Wendy (2010) have proposed a new "Digital Age Communications Act" to provide a legislative framework for the FTC to undertake $e x$ post review of content discrimination claims under the antitrust laws. However, it is crucial to keep in mind that competition policy, whether undertaken under existing antitrust statutes or new communications regulations, is not a remedy for a problem based on a failure to internalize network externalities, not the exercise of inordinate market power.

A final potential side benefit to a general minimum quality standard merits mention. Much of the concerns motivating net neutrality involve horror stories in which a broadband provider limited access not to reap market power but to influence political debate. Noted examples include the Canadian Internet provider Telus blocking access to the Telecommunications Workers Union website during a labor dispute and AOL blocking emails that mentioned a website for a group opposing AOL's proposed payments for

\footnotetext{
${ }^{11}$ Supra $\mathrm{n} .1$

${ }^{12}$ More speculatively, if fiber to the home restores becomes the natural monopoly provider of highspeed broadband access for which wireless broadband is not an effective substitute, we could return to an era of telecommunications price regulation. Evasion of such regulation was at the heart of the antitrust case leading to the breakup of AT\&T in 1984, but the Supreme Court's decision in Verizon v. Trinko, 540 U.S. 398 (2004) effectively turned the argument on its head, finding that FCC oversight rendered the benefits of antitrust enforcement over telecommunications interconnection less than the cost (Brennan, 2005).
} 
sending email (Ganley and Allgrove, 2006 at 458). In many respects, concern over access control that threaten speech rights consistent with First Amendment traditions should be more pronounced not when monopolies maximize profits, but when they sacrifice profits to make political points (Brennan, 1990). ${ }^{13}$ This policy concern may not fall easily within economic models of market success and market failure. But a significant side benefit of a minimum quality standard, justified by the enhancement of network externalities, could be that it would provide along the way a relatively unobtrusive remedy for preventing infringement of speech rights.

\footnotetext{
${ }^{13}$ It is not clear that in the U.S. that, on this score, the law would be on the side of net neutrality advocates. In the U.S., following the then AT\&T's divestiture of its local exchange carries (LECs), the LECs argued in favor of lifting restrictions on offering information services as limitations on their free speech rights. Cable companies used similar arguments to prevent local governments from shutting the cable incumbents down in order to offer franchises to competitors. The underlying idea is that the right to speech inheres in the ownership of the relevant physical assets, not in the speaker's right to be heard (Brennan, 1989). This raises the question of whether a broadband provider could deny service to or access to websites from those who support net neutrality, minimum quality standards, or other regulations.
} 


\section{References}

Brennan, Timothy, “The 'Fairness Doctrine' as Public Policy,” Journal of Broadcasting and Electronic Media 33 (1989): 419-40.

Brennan, Timothy, "Vertical Integration, Monopoly, and the First Amendment," Journal of Media Economics 3 (1990): 57-76.

Brennan, Timothy, "Industry Parallel Interconnection Agreements," Information Economics and Policy 9 (1997): 133-149.

Brennan, Timothy, "Trinko v. Baxter: The Demise of U.S. v. AT\&T," Antitrust Bulletin, 50 (2005): 635-64.

Brennan, Timothy, "Essential Facilities and Trinko: Should Antitrust and Regulation Be Combined?" Federal Communications Law Journal 61 (2008): 133-47.

Brennan, Timothy, "Commentary: Bright Lines and Cautionary Notes," in Boyer, Marcel, Michael Trebilcock and David Vaver (eds.), Competition Policy and Intellectual Property (Toronto: Irwin Law, 2009a): 226-45.

Brennan, Timothy, "Network Effects in Infrastructure Regulation: Principles and Paradoxes," Review of Network Economic 8 (2009b): 279-301.

Brito, Jerry, et. al., "Net Neutrality Regulation: The Economic Evidence," Before the Federal Communications Commission, In the Matter of Preserving the Open Internet Broadband Industry Practices, GN Docket No. 09-191 (April 12, 2010), available at http://ssrn.com/abstract=1587058.

Carlton, Dennis and Ken Heyer, "Extraction vs. Extension: The Basis For Formulating Antitrust Policy Towards Single-Firm Conduct," Competition Policy International 4 (2008): 285-305.

Choi, Jay Pil and Kim, Byung-Cheol, "Net Neutrality and Investment Incentives," NET Institute Working Paper No. 08-03. (September 2008), available at http://ssrn.com/abstract=1285639.

Economides, Nicholas, “"Net Neutrality,' Non-Discrimination and Digital Distribution of Content Through the Internet," I/S: A Journal of Law and Policy for the Information Society 4 (2008): 209-33.

Economides, Nicholas and Joacim Tåg, "Net Neutrality on the Internet: A Two-Sided Market Analysis" (May 2009), available at http://ssrn.com/abstract=1019121. 
Farrell, Joseph and Phillip Weiser, "Modularity, Vertical Integration, and Open Access Policies: Towards a Convergence of Antitrust and Regulation in the Internet Age," Harvard Journal of Law and Technology 17 (2003): 85-134.

Faulhaber, Gerald and David Farber, "The Open Internet: A Customer-Centric Framework," International Journal of Communication 4 (2010): 302-42.

Ford, George and Michael Stern, "Sabotaging Content Competition: Do Proposed Net Neutrality Regulations Promote Exclusion?” Phoenix Center Perspectives 10-02 (March 4, 2010), available at http://ssrn.com/abstract=1576565.

Froeb, Luke M. and Ganglmair, Bernhard, "Innovation, Patent Hold-Up, and Equilibrium Effects of RAND Commitments," Vanderbilt Law and Economics Research Paper No. 09-11 (2009), available at http://ssrn.com/abstract=1340722.

Ganley, Paul and Ben Allgrove, "Net Neutrality: A User's Guide," Computer Law and Security Report 22 (2006): 454-63.

Government Accounting Office, "FCC Needs to Improve Oversight of Wireless Phone Service," GAO-10-34 (November 2009), available at http://www.gao.gov/new.items/d1034.pdf.

Hahn, Robert and Scott Wallsten, “The Economics of Net Neutrality," Economists' Voice (June 2006): 1-7.

Hazlett, Thomas, "Is Federal Pre-emption Efficient in Cellular Telephone Regulation?" Federal Communications Law Journal 56 (2003): 155-237.

Iacobucci, Edward and Ralph Winter, "Tying and Intellectual Property," in Boyer, Marcel, Michael Trebilcock and David Vaver (eds.), Competition Policy and Intellectual Property (Toronto: Irwin Law, 2009): 165-225.

Katz, Michael, "The Welfare Effects of Third Degree Price Discrimination in Intermediate Goods Markets," American Economic Review 77 (1987): 154-67.

Krämer, Jan and Lukas Wieworra, "Innovation Through Discrimination? A Formal Analysis of the Net Neutrality Debate" (March 2010), available at http://mpra.ub.unimuenchen.de/22095/1/MPRA paper_22095.pdf.

Lee, Robin and Tim Wu, "Subsidizing Creativity Through Network Design: Zero-Pricing and Net Neutrality," Journal of Economic Perspectives 23 (2009): 61-76.

Litan, Robert and Hal Singer, "Unintended Consequences of Net Neutrality Regulation," Journal on Telecommunications \& High Technology Law 5 (2007): 533-64.

Mayo, John, et. al., "How to Regulate the Internet Trap," New York Times (April 21, 2010). 
Musacchio, John, Galina Schwartz and Jean Walrand, "A Two-Sided Market Analysis of Provider Investment Incentives with an Application to the Net-Neutrality Issue," Review of Network Economics 8 (2009): 22-39.

Rochet, Jean-Charles and Jean Tirole, "Two-Sided Markets: A Progress Report," RAND Journal of Economics 37 (2006): 645-667.

Schuett, Florian, "Network Neutrality: A Survey of the Economic Literature," TILEC Discussion Paper DP 2010-014 (March 2010), available at http://ssrn.com/abstract=1573420.

Schwartz, Marius and Philip Weiser, "Introduction to a Special Issue on Network Neutrality," Review of Network Economics 8 (2009): 1-12.

Sidak, J. Gregory, "A Consumer-Welfare Approach to Network Neutrality Regulation of the Internet," Journal of Competition Law and Economics 2 (2006): 349-474.

Sidak, J. Gregory, "Patent Holdup and Oligopsonistic Collusion in Standard-Setting Organizations," Journal of Competition Law and Economics 5 (2009): 123-88.

Thierer, Adam and Mike Wendy, Mike, "The Constructive Alternative to Net Neutrality Regulation and Title II Reclassification Wars," (May 19, 2010). Progress on Point 17(9) (2010): 1-9, available at http://ssrn.com/abstract=1614884.

Whinston, Michael, "Tying, Foreclosure and Exclusion," American Economic Review 80 (1990): 837-59.

Wright, Joshua, "Why the Supreme Court was Correct to Deny Certiorari in FTC v. Rambus," George Mason Law \& Economics Research Paper No. 09-14 (2009), available at http://ssrn.com/abstract=1349969.

Yoo, Christopher, "Network Neutrality or Internet Innovation," Regulation (Spring 2010): 22-29. 